\title{
Isolation and structure elucidation of the nucleoside antibiotic strepturidin from Streptomyces albus DSM 40763
}

\author{
Alexander Pesic ${ }^{1,4}$, Britta Steinhaus ${ }^{2,4}$, Sebastian Kemper ${ }^{1}$, Jonny Nachtigall ${ }^{1}$, Hans Jürgen Kutzner ${ }^{3}$, \\ Gerhard Höfle $^{2}$ and Roderich D Süssmuth ${ }^{1}$
}

The antibiotic strepturidin (1) was isolated from the microorganism Streptomyces albus DSM 40763, and its structure elucidated by spectroscopic methods and chemical degradation studies. The determination of the relative and absolute stereocenters was partially achieved using chiral GC/EI-MS analysis and microderivatization by acetal ring formation and subsequent 2D-NMR analysis of key ${ }^{1} \mathrm{H},{ }^{1} \mathrm{H}$-NOESY NMR correlations and extraction of ${ }^{1} \mathrm{H},{ }^{13} \mathrm{C}$ coupling constants from ${ }^{1} \mathrm{H},{ }^{13} \mathrm{C}$-HMBC NMR spectra. Based on these results, a biosynthesis model was proposed.

The Journal of Antibiotics (2014) 67, 471-477; doi:10.1038/ja.2014.16; published online 5 March 2014

Keywords: 2D NMR; chiral GC/EI-MS analysis; nucleoside antibiotic; stereochemistry; Streptomyces; structure elucidation

\section{INTRODUCTION}

The genus Streptomyces (Order Actinomycetales, colloquial 'Actinomycetes') is a widely studied genus of the Actinomycete family. Among all Actinomycetes, Streptomycetes play an important role in drug discovery as from this genus $90 \%$ of the more than 3000 known antibiotics have been isolated. ${ }^{1}$ In comparison with other Gram-positive bacteria like Staphylococcus, Streptococcus and Bacillus, the GC-content of the DNA of Streptomyces is with $\sim 70 \%$ comparatively high. Examples of prominent antibiotics produced by these bacteria are the aminoglycoside streptomycin (antituberculosis), the chromopeptide actinomycin (cytostatic) and the polyketide tetracycline (antibacterial).

Here we report on an antibiotic compound produced by Streptomyces albus that exhibits a specific antibacterial activity against the Gram-negative nitrogen-fixing soil bacterium Azotobacter chroococcum. $^{2}$ This antibacterial activity has been initially discovered in 1956 by Kutzner $^{3}$ (see also Flaig and Kutzner ${ }^{4}$ ), and, as shown later by Böttiger, ${ }^{5}$ extends to all other members of the family Azotobacteraceae. However, this antibacterial effect is independent from the nitrogen status of the medium and therefore the nitrogenase system of Azotobacter has been excluded as a molecular target. ${ }^{6}$ The first isolation of the active compound, named strepturidin (1), and its preliminary structure elucidation has already been described by Steinhaus ${ }^{7}$ in 1993. Initial attempts to characterize the new antibiotic substance with the above-mentioned features by test reactions proved positive for guanidine-groups, sugars and amino sugars. However, test reactions yielded negative results for aromatic amines, organic acids, amino acids and peptides.
This report presents in detail the cultivation of the producing strain, as well as the isolation and structure elucidation of the nucleoside antibiotic strepturidin (1), by means of HPLC-HR-ESI(+)-Orbitrap-MS, chiral GC/EI-MS, extensive 2D-NMR spectroscopy including partial assignment of the relative stereochemistry and absolute stereochemistry. Based on the investigations on the structure elucidation and determination of the stereochemistry, we postulated a plausible biosynthesis model for (1).

\section{RESULTS}

Producing strain and bacterium for antibiotic assay

S. albus has been extensively characterized in the past, notably by Gordon et al., ${ }^{6}$ Böttiger ${ }^{5}$ and Herrmann. ${ }^{8}$ This streptomycete species can be easily isolated from its natural habitat, that is, self-heated hay or compost, and can be rapidly identified by classical properties. The strain DSM 40763 has been selected from the numerous representatives of this species, which are kept in worldwide culture collections. For the antibacterial assay, the strain A. chroococcum DSM 281 has been employed.

Cultivation and isolation of strepturidin (1)

S. albus DSM 40763 was cultivated as described by Herrmann. ${ }^{8}$ With a seed culture of $200 \mathrm{ml}$, a 101 preculture was inoculated to be used subsequently to inoculate the production fermenter containing 801 of complex medium (mannitol $10 \mathrm{gl}^{-1}$, soy meal (full-fat) $10 \mathrm{gl}^{-1}$, meat extract $5 \mathrm{gl}^{-1}$, sodium chloride $1 \mathrm{gl}^{-1}$, calcium carbonate $1 \mathrm{gl}^{-1}$, tegosipon $10 \mathrm{ml}$ ). The cultivation was carried out at $37^{\circ} \mathrm{C}$ at 300 r.p.m.

\footnotetext{
${ }^{1}$ Institut für Chemie, Technische Universität Berlin, Berlin, Germany; ${ }^{2}$ Helmholtz Zentrum für Infektionsforschung, Braunschweig, Germany and ${ }^{3}$ Technische Hochschule Darmstadt, Institut für Mikrobiologie und Genetik, Darmstadt, Germany

${ }^{4}$ These authors contributed equally to this work.

Correspondence: Professor RD Süssmuth, Institut für Chemie, Technische Universität Berlin, Straße des 17. Juni 124, 10623 Berlin, Germany.

E-mail: suessmuth@tu-berlin.de
}

Received 5 November 2013; revised 20 January 2014; accepted 27 January 2014; published online 5 March 2014 


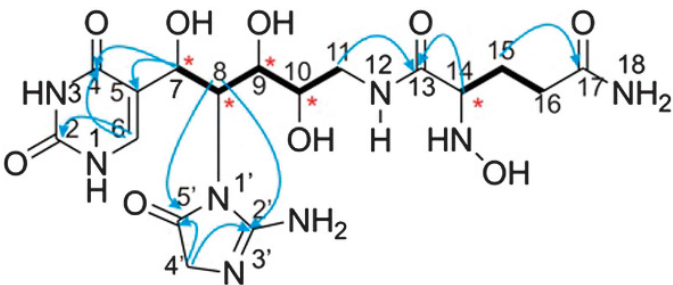

Figure 1 Structure of strepturidin (1). Bold lines indicate ${ }^{1} \mathrm{H},{ }^{1} \mathrm{H}$-COSY correlations. Blue arrows indicate ${ }^{1} \mathrm{H},{ }^{13} \mathrm{C}-\mathrm{HMBC}$ correlations. Asterisks mark the five stereogenic centers. The list of chemical shifts is summarized in Table 1.

and an aeration of 0.5 v.v.m. Growth and antibiotic production were monitored by wet cell mass weight and HPLC analysis, respectively. After $26 \mathrm{~h}, 130 \mathrm{gl}^{-1}$ wet cell mass and an antibiotic titer of $92 \mathrm{mgl}^{-1}$ were determined. The culture broth was harvested by centrifugation, sodium heptanesulfonate was added to the supernatant and the crude antibiotic obtained by ion-pair extraction on Amberlite XAD-16 (Sigma-Aldrich, Taufkirchen, Germany). From the eluate of the resin an excess of sodium heptanesulfonate was extracted as an ion-pair with methyltrioctylammonium chloride using dichloromethane as the solvent. Further purification was carried out by preparative RP18 HPLC and desalting with Amberlite XAD-16 followed by CM-Sephadex $\mathrm{NH}_{4}{ }^{+}$chromatography as described below. After purification, $1.76 \mathrm{~g}$ of pure strepturidin (1) was obtained as a white powder with no defined m.p.

\section{Structure elucidation by means of MS and NMR}

The exact molecular mass of $(\mathbf{1})\left(\mathrm{m} / z\right.$ found $\left.486.19193[\mathrm{M}+\mathrm{H}]^{+}\right)$ derived from the HR-ESI- $(+)$-Orbitrap-MS analysis $(\mathrm{m} / \mathrm{z}$ calcd $486.18227[\mathrm{M}+\mathrm{H}]^{+}, \Delta \mathrm{m} 4.883$ p.p.m.) gave a molecular formula of $\mathrm{C}_{17} \mathrm{H}_{27} \mathrm{O}_{9} \mathrm{~N}_{8}[\mathrm{M}+\mathrm{H}]^{+}$. The IR spectrum showed absorptions for amine and hydroxyl groups $\left(3341,2928 \mathrm{~cm}^{-1}\right)$ and amide carbonyls $\left(1662 \mathrm{~cm}^{-1}\right)$ but no characteristic bands for aromatic hydrocarbons were detected below $900 \mathrm{~cm}^{-1}$ (C-H deformation vibration). The UV spectrum showed a maximum at $\lambda=262 \mathrm{~nm}(\varepsilon$ 3.89) and displayed characteristic absorptions for heterocycles such as nucleobases. Subsequently to the determination of these parameters, the structure elucidation of (1) (Figure 1) was established from extensive use of ${ }^{1} \mathrm{H}$ - and 2D-NMR experiments $\left({ }^{1} \mathrm{H},{ }^{1} \mathrm{H}\right.$-COSY, ${ }^{1} \mathrm{H},{ }^{13} \mathrm{C}-\mathrm{HMBC}$, ${ }^{1} \mathrm{H},{ }^{13} \mathrm{C}-\mathrm{HSQC},{ }^{13} \mathrm{C}$-NMR and ${ }^{13} \mathrm{C}$-DEPT) in $d_{6}$-DMSO that revealed a composition of the molecule from four distinct building blocks. The chemical shifts are summarized in Table 1. In the following a more detailed analysis of the NMR data is given.

The structure elucidation of (1) commenced with the interpretation of the ${ }^{1} \mathrm{H}-\mathrm{NMR}$ (Table 1 ) and ${ }^{13} \mathrm{C}$-DEPT NMR spectra. ${ }^{7}$ The ${ }^{1} \mathrm{H}-\mathrm{NMR}$ spectrum of (1) reveals 14 proton NMR signals, with 8 aliphatic methylene $\left(\mathrm{CH}_{2}\right)$ protons, 5 aliphatic protons and 1 olefinic methine $(\mathrm{CH})$ proton. In analogy to the ${ }^{1} \mathrm{H}-\mathrm{NMR}$, the ${ }^{13} \mathrm{C}$-DEPT NMR spectrum reveals the corresponding signals of four methylene, six methine and, in addition, seven quaternary carbon signals. No primary carbons as represented by methyl groups were detected.

The NMR data of (1) can be formally divided into four spin systems. The first spin system was identified as the glutamine (Gln) Gln- $N_{\alpha}$-hydroxamate with four methylene protons at $\delta_{\mathrm{H}-16}$ 2.07 p.p.m. ( $\left({ }^{3}{ }^{3} \mathrm{H}-16, \mathrm{H}-15=7.2 \mathrm{~Hz}, 2 \mathrm{H}\right)$ and at $\delta_{\mathrm{H}-15} 1.9$ p.p.m. $(\mathrm{m}$, $2 \mathrm{H})$ and a single aliphatic methine proton at $\delta_{\mathrm{H}-14} 4.7$ p.p.m. $(\mathrm{t}$, $\left.{ }^{3} J_{\mathrm{H}-14, \mathrm{H}-15}=3.3 \mathrm{~Hz},{ }^{3} J_{\mathrm{H}-14, \mathrm{NH}}=8.6 \mathrm{~Hz}, 1 \mathrm{H}\right)$. The Gln- $N_{\alpha}$-hydroxamate spin system is linked through its $\alpha$-carbonyl at $\delta_{\mathrm{C}-13} 169.8$ p.p.m. to form an amide $\left(\delta_{\mathrm{NH}-12} 8.4\right.$ p.p.m. $\left.(\mathrm{b}, 1 \mathrm{H})\right)$ with the amino group of
Table 1 NMR spectroscopic data for strepturidin (1) and monoacetal-strepturidin (3) $(500 \mathrm{MHz})$ in $d_{6-}$ DMSO

\begin{tabular}{|c|c|c|c|c|}
\hline \multirow[b]{2}{*}{ Pos. } & \multicolumn{2}{|c|}{ Strepturidin $(\mathbf{1})^{a}$} & \multicolumn{2}{|c|}{ Monoacetal-strepturidin (3) } \\
\hline & $\begin{array}{c}\delta_{H} \text { in p.p.m. } \\
\text { (multiplicity, } \\
\text { integral, } \mathrm{J} \text { in } \mathrm{Hz} \text { ) }\end{array}$ & $\begin{array}{c}\delta_{C} \text { in p.p.m. } \\
\text { multiplicity }\end{array}$ & $\begin{array}{c}\delta_{H} \text { in p.p.m. } \\
\text { (multiplicity, } \\
\text { integral, } \mathrm{J} \text { in } \mathrm{Hz} \text { ) }\end{array}$ & $\begin{array}{r}\delta_{C} \text { in p.p.m. } \\
\text { multiplicity }\end{array}$ \\
\hline 1 & l & - & l & - \\
\hline 2 & - & 155.9, qC & - & 152.3, qC \\
\hline 3 & I & - & l & - \\
\hline 4 & - & $165.4, q C$ & - & 164.0, qC \\
\hline 5 & - & 109.1, qC & - & $110.4, \mathrm{qC}$ \\
\hline 6 & $7.34(\mathrm{~s}, 6.4,-)$ & $145.4, \mathrm{CH}$ & $7.50(\mathrm{~s}, 1,-)$ & $140.4, \mathrm{CH}$ \\
\hline 7 & $4.37(d, 1,5.5)$ & $79.9, \mathrm{CH}$ & $4.60(d, 1,3.2)$ & $79.4, \mathrm{CH}$ \\
\hline 8 & $3.85(\mathrm{dd}, 1,5.4)$ & $71.8, \mathrm{CH}$ & $4.83(\mathrm{dd}, 1,6.3 ; 3.3)$ & $84.2, \mathrm{CH}$ \\
\hline 9 & $3.64(d d, 1,5.0)$ & $73.8, \mathrm{CH}$ & $4.68(/, \mathrm{m} \text {, overlap })^{\mathrm{b}}$ & $82.8, \mathrm{CH}$ \\
\hline 10 & 3.77 (ddd, 1, 4.0) & 81.3, $\mathrm{CH}$ & $3.70(\mathrm{dd}, 1,5.2)$ & $81.2 \mathrm{CH}$ \\
\hline 11 & $3.16 ; 3.52(/, 2, /)^{c}$ & $40.7, \mathrm{CH}_{2}$ & $\begin{array}{l}3.18(/, /, /) ; \\
3.25(/, / /, /)\end{array}$ & $40.6 \mathrm{CH}_{2}$ \\
\hline 12 & $8.44(\mathrm{~s}, \mathrm{~b}, 1.0)$ & - & I & - \\
\hline 13 & - & 169.8, qC & - & 169.3, qC \\
\hline 14 & $4.77(t, 1,3.3,8.6)$ & $59.0, \mathrm{CH}$ & 4.70 (m, overlap, /) & $59.4, \mathrm{CH}$ \\
\hline 15 & $1.99(\mathrm{~m}, 2, /)$ & $23.9, \mathrm{CH}_{2}$ & $2.11 / 1.94(\mathrm{~m}$, overlap, /) & 23.3, $\mathrm{CH}_{2}$ \\
\hline 16 & $2.07(t, 2,7.2)$ & $31.8, \mathrm{CH}_{2}$ & $2.08(\mathrm{~m}$, overlap, /) & $31.6, \mathrm{CH}_{2}$ \\
\hline 17 & - & 174.1, qC & - & 174.7, qC \\
\hline 18 & $\begin{array}{c}6.77(\mathrm{~s}, 1,-) \\
7.3(\mathrm{~s}, 1,-)\end{array}$ & - & $6.8(\mathrm{br}, 2,-)$ & - \\
\hline $1^{\prime}$ & - & - & - & - \\
\hline $2^{\prime}$ & - & 157.6, qC & - & 157.9, qC \\
\hline $3^{\prime}$ & - & - & - & - \\
\hline $4^{\prime}$ & $4.20(\mathrm{~s}, 2,-)$ & $42.1, \mathrm{CH}_{2}$ & $4.18(\mathrm{~m}, 2, /)$ & $42.8 \mathrm{CH}_{2}$ \\
\hline $5^{\prime}$ & - & 168.1, qC & - & 169.2, qC \\
\hline $1^{\prime \prime}$ & - & - & $1.55(\mathrm{~s}, 3,-)$ & $28.4, \mathrm{CH}_{3}$ \\
\hline $2^{\prime \prime}$ & - & - & - & 113.5, qC \\
\hline $3^{\prime \prime}$ & - & - & - & 144.1, qC \\
\hline $4^{\prime \prime}$ & - & - & $7.35(/, /, /)$ & $127,7 \mathrm{CH}$ \\
\hline $5^{\prime \prime}$ & - & - & $7.52(\mathrm{~d}, 2,7.7)$ & $124,0 \mathrm{CH}$ \\
\hline $6^{\prime \prime}$ & - & - & $7.37(/, /, /)$ & $124,0 \mathrm{CH}$ \\
\hline
\end{tabular}

The symbol ' $/$ ' indicates not assigned and ' -' indicates not available.

as reported by Steinhaus.

${ }^{b}$ Overlap in ${ }^{1} \mathrm{H}-\mathrm{NMR}$, coupling constants could not be determined.

${ }^{\mathrm{C}} \mathrm{ABX}$-System, AB-Part with broad lines.

the subsequent spin system identified as a triol-containing carbon chain, an open-chain aldopentose derivative named diamino aldopentose. The linkage was assigned from the methylene protons of the diamino aldopentose alkyl spin system at $\delta_{\mathrm{H}-11} 3.2 / 3.5$ p.p.m. (br, $2 \mathrm{H}$; ABX-part, $\mathrm{AB}$-part with broad lines) correlating to $\delta_{\mathrm{C}-13} 169.8$ p.p.m. in the ${ }^{1} \mathrm{H},{ }^{13} \mathrm{C}-\mathrm{HMBC}$ NMR spectrum. ${ }^{7}$ From the remaining four aliphatic proton signals present in this spin system, three methine protons $(\mathrm{CH})$ at $\delta_{\mathrm{H}-7} 4.3$ p.p.m. $\left(\mathrm{d},{ }^{3} J_{\mathrm{H}-7, \mathrm{H}-8}=5.5 \mathrm{~Hz}, 1 \mathrm{H}\right), \delta_{\mathrm{H}-9}$ 3.6 p.p.m. (dd, $\left.{ }^{3} J=5 \mathrm{~Hz}, 1 \mathrm{H}\right)$ and $\delta_{\mathrm{H}-10} 3.7$ p.p.m. (ddd, ${ }^{3} J=4 \mathrm{~Hz}$, $1 \mathrm{H})$ are bound to three carbons bearing hydroxyl groups. One additional aliphatic methine proton at $\delta_{\mathrm{H}-8} 3.8$ p.p.m. $(\mathrm{dd}$, $\left.{ }^{3} J=5.4 \mathrm{~Hz}, 1 \mathrm{H}\right)$ is connecting a third spin system identified as an 2-aminoimidazol-5-one moiety through ${ }^{1} \mathrm{H},{ }^{13} \mathrm{C}-\mathrm{HMBC}$ correlations to the quaternary carbons at $\delta_{\mathrm{C}-2^{\prime}} 157.6$ p.p.m. and $\delta_{\mathrm{C}-5^{\prime}} 168.1$ p.p.m., respectively. In addition, the 2-aminoimidazol-5-one spin system accommodates the remaining two methylene protons of structure (1) at $\delta_{\mathrm{H}-4^{\prime}} 4.2$ p.p.m. $(\mathrm{s}, 2 \mathrm{H})$. The final spin system constitutes the nucleobase uracil that is attached via a C-C-bond to the open-chain 
a

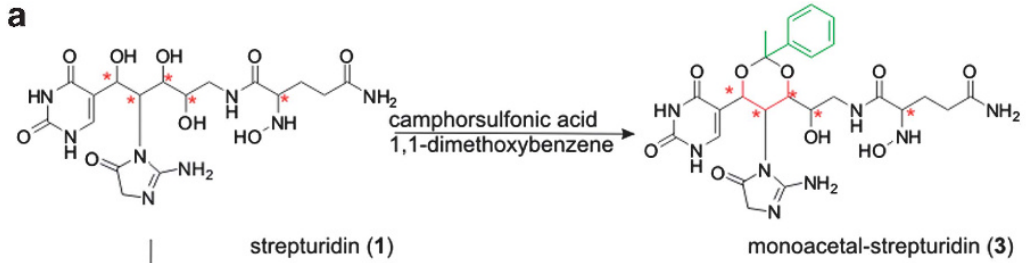

$\mathrm{Zn}, 2 \mathrm{~h}$

$2 \mathrm{~N} \mathrm{HCl}$
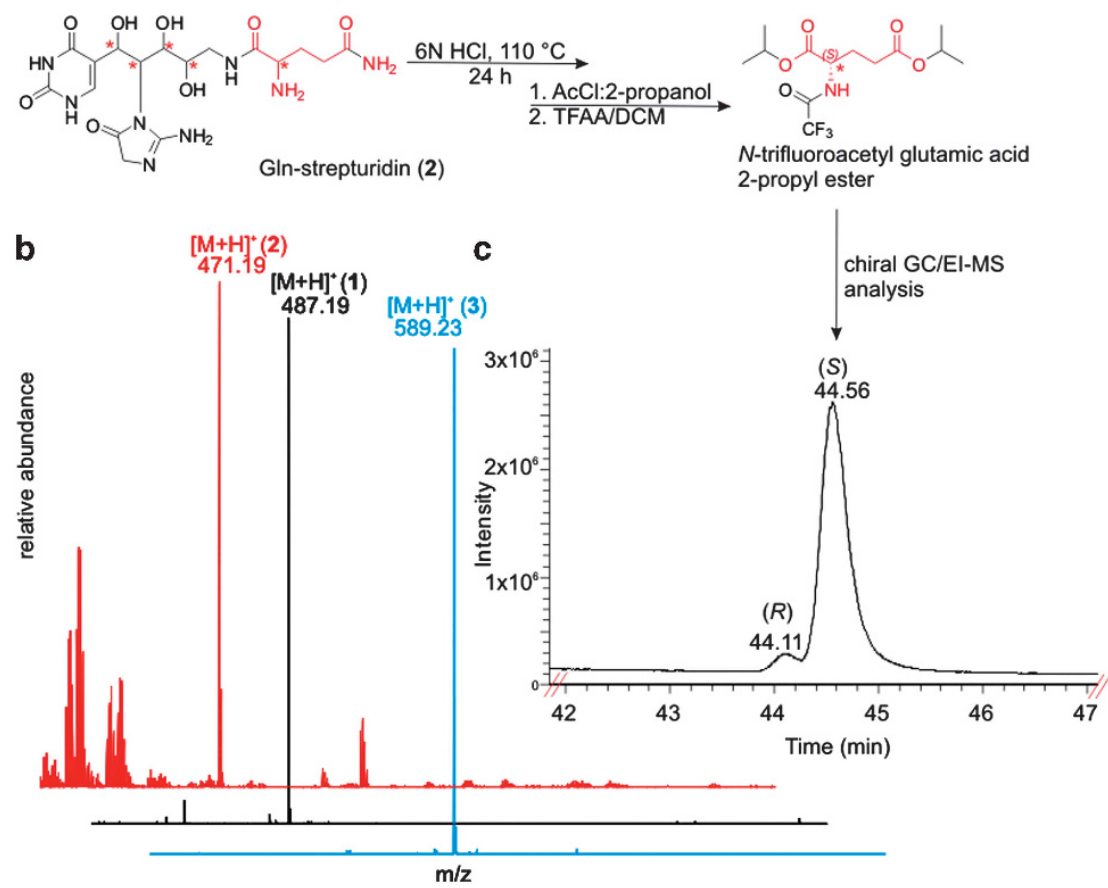

Figure 2 (a) Scheme for preparative microreactions performed with strepturidin (1). Formation of monoacetal-strepturidin (3) with 1,1-dimethoxybenzene and camphorsulfonic acid for 2D-NMR experiments. Reduction of strepturidin (1) to GIn-strepturidin (2) for chiral GC/EI-MS analysis. (b) HR-HPLC-ESI$(+)$-Orbitrap-MS data of the compounds (1-3). (c) chiral GC-chromatogram on a LIPPDEX E column. Enantiomer analytics of $(R / S)$ - $N$-trifluoroacetyl Glu 2-propyl esters (Rt- $(S)=44.56 \mathrm{~min}, \mathrm{Rt}-(R)=44.11 \mathrm{~min}$ ) after hydrolysis and derivatization of Gln-strepturidin (2). The El-MS spectrum of $\mathrm{N}$-trifluoroacetyl (S) Glu 2-propyl ester at Rt $=44.56 \mathrm{~min}$ is shown in Supplementary Figure S4B. Asterisks mark the stereocenters in strepturidin (1).

diamino aldopentose moiety similar to the $C$-linkage of the ring ribose to uracil in pseudouridine $(\psi)$. This finding is corroborated by the presence of only one single characteristic olefinic methine proton at $\delta_{\mathrm{H}-6} 7.60$ p.p.m. $(\mathrm{s}, 1 \mathrm{H})$ as a part of the uracil structure. These data are complemented by the quaternary carbon signals at $\delta_{\mathrm{C}-2}$ 155.9 p.p.m., $\delta_{\mathrm{C}-4} 165.4$ p.p.m., $\delta_{\mathrm{C}-5} 109.1$ p.p.m. and the olefinic methine signal at $\delta_{\mathrm{C}-6} 145.4$ p.p.m. as part of the nucleobase uracil. The complete structure elucidation is further complemented by ${ }^{1} \mathrm{H},{ }^{13} \mathrm{C}-\mathrm{HSQC}$ NMR data ${ }^{7}$ yielding the assigned protons together with their corresponding carbon atoms and the correlations within the spin parts by the ${ }^{1} \mathrm{H},{ }^{1} \mathrm{H}$-COSY experiment. ${ }^{7}$ Figure 1 shows the structure of strepturidin (1) with the key ${ }^{1} \mathrm{H},{ }^{13} \mathrm{C}-\mathrm{HMBC}$ contacts with blue arrows and the ${ }^{1} \mathrm{H},{ }_{1}^{1} \mathrm{H}$-COSY correlations in bold lines.

\section{Assignment of the absolute stereochemistry in the Gln- $N_{\alpha}$-hydroxamate moiety}

The above structure elucidation of (1) revealed the constitutional formula and left the relative and absolute stereochemistry of the five stereocenters at C-7, C-8, C-9, C-10 and C-14 unassigned (Figure 1). Various attempts to crystalize the substance failed, most likely because of the high polarity, structural flexibility and also instability of the molecule (1). Therefore, the subsequent experiments focused on derivatization reactions to assign a maximum number of stereocenters.

Our efforts started with the carbon C-14 that is the stereocenter of the Gln- $N_{\alpha}$-hydroxamate. The stereochemistry at C-14 was determined by reduction of the $N_{\alpha}$-hydroxyl amine group with $2 \mathrm{~N} \mathrm{HCl} / \mathrm{Zn}(2 \mathrm{~h}$, room temperature) and transformation into the corresponding amino acid Gln (Figure 2a), generating Gln-strepturidin (2). The reduction was followed by HPLC-HR-ESI- $(+)$-Orbitrap-MS (Figure 2b) and HPLCLR-ESI- $(+)-$ MS $^{2}$ (Supplementary Figure S3). Subsequently, reduced Gln-strepturidin (2) (Figure 2a) was hydrolyzed $\left(6 \mathrm{~N}, \mathrm{HCl}, 24 \mathrm{~h}, 110^{\circ} \mathrm{C}\right.$, under vacuum) to obtain the glutamic acid (Glu) that was derivatized to the $N$-trifluoroacetyl 2-propyl ester. Amino acid analysis by chiral GC/EI-MS on a LIPODEX E (Macherey-Nagel, Düren, Germany) column (Figure 2c) revealed that the $N$-trifluoroacetyl Glu 2-propyl ester has $(S)$-configuration. Based on these results, the stereocenter at $\mathrm{C}-14$ in (1) is also $(S)$-configured.

\section{Assignment of the relative stereochemistry in the aldopentose moiety}

The relative configuration of the remaining four stereocenters in the central part of the molecule C-7 to C-10 could not be derived by the 

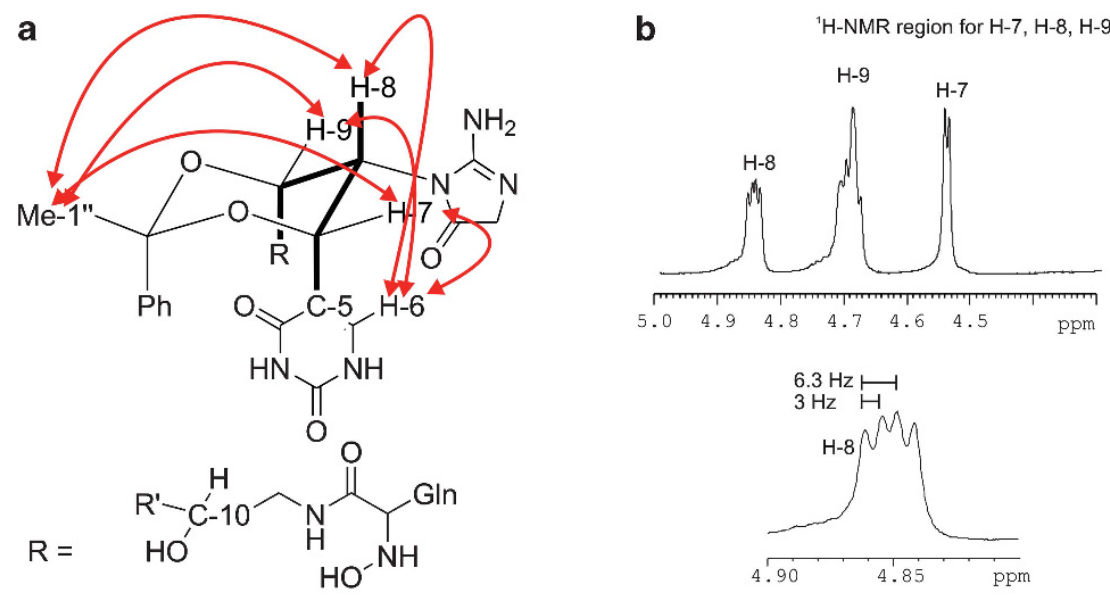

$\mathrm{R}^{\prime}=\mathrm{C}-1$ - C-9 of monoacetal-Strepturidin (3)

C

${ }^{1} \mathrm{H},{ }^{13} \mathrm{C}-\mathrm{HMBC}$

Traces in F2 @ C-10 (84 ppm)

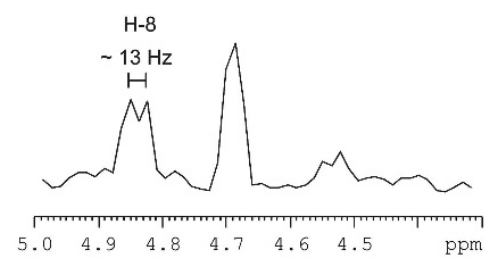

d

${ }^{1} \mathrm{H},{ }^{13} \mathrm{C}-\mathrm{HMBC}$

Traces in F2 @ C-5 (110 ppm)

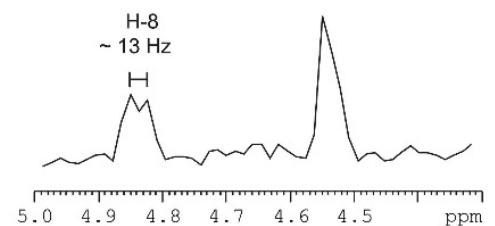

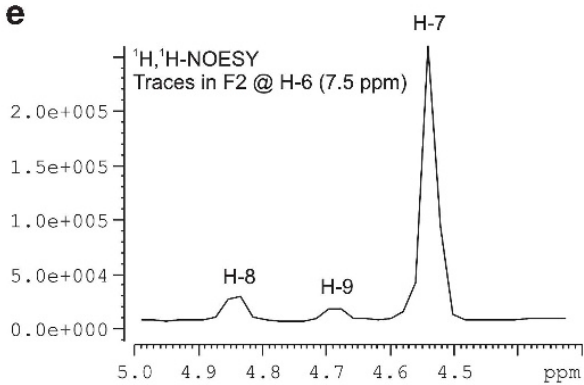

f

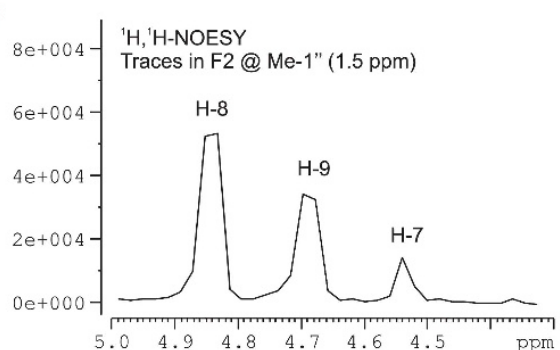

Figure 3 NMR analysis of monoacetal-strepturidin (3). (a) Plausible model for 1,3 acetal based on NMR analysis. Red arrows indicate ${ }^{1} \mathrm{H},{ }^{1} \mathrm{H}-\mathrm{NOESY}$ contacts. Bold lines indicate ${ }^{3} \mathrm{~J}_{\mathrm{H}-8, \mathrm{C}-10}$ and ${ }^{3} \mathrm{~J}_{\mathrm{H}-8, \mathrm{C}-5}$ correlations. (b) ${ }^{1} \mathrm{H}-\mathrm{NMR}$ region for the three key protons $\mathrm{H}-7$, $\mathrm{H}-8$ and $\mathrm{H}-9$ for compound (3) and expanded ${ }^{1} \mathrm{H}-\mathrm{NMR}$ region for $\mathrm{H}-8$. (c) Traces in $\mathrm{F} 2$ extracted from ${ }^{1} \mathrm{H},{ }^{13} \mathrm{C}-\mathrm{HMBC}$ spectra for $\mathrm{C}-10$ and $\mathrm{C}-5$ (d). The coupling constants ${ }^{3} J_{\mathrm{H}-8, \mathrm{C}-10} \approx 10-13 \mathrm{~Hz}$ and ${ }^{3} \mathrm{~J}_{\mathrm{H}-8, \mathrm{C}-5} \approx 10-13 \mathrm{~Hz}$ suggest an axial orientation. (e) Traces in F2 extracted from ${ }^{1} \mathrm{H},{ }^{1} \mathrm{H}-\mathrm{NOESY}$ spectra for $\mathrm{H}-6$. (f) Traces in F2 extracted from ${ }^{1} \mathrm{H},{ }^{1} \mathrm{H}-\mathrm{NOESY}$ spectra for the methyl group Me- ${ }^{\prime \prime}$. The weak NOE between $\mathrm{H}-6$ and $\mathrm{H}-8$ in (e) cannot be explained with the conformation shown in (a). Probably, a second conformer with $\mathrm{H}-8$ and uracil in equatorial position exists.

${ }^{13} \mathrm{C}-\mathrm{NMR}$ spectroscopic database approach developed by Kishi and coworkers $^{9}$ as these databases are only applicable for 1,3-acetals with a methylene group $\left(\mathrm{CH}_{2}\right)$ connecting the diol groups. In order to reduce the polarity and to increase the rigidity of the molecule for additional NMR spectroscopy experiments of (1), we considered transformation of the 1,3-diol unit into the corresponding 1,3-acetal using 1,1-dimethoxyethylbenzene and camphorsulfonic acid ${ }^{10}$ (Figure 2a) to give the monoacetal-strepturidin (3) $(\mathrm{m} / \mathrm{z} 589.2$ $\left.[\mathrm{M}+\mathrm{H}]^{+}\right)$. The monoacetal-strepturidin (3) was isolated by preparative reversed-phase C18-HPLC (Supplementary Figure S1).

The formation of the six-membered 1,3-acetal of compound (3) was proven by ${ }^{1} \mathrm{H}-\mathrm{NMR}$ (Supplementary Figure S5) and 2D-NMR experiments (Supplementary Figures $\mathrm{S} 7-\mathrm{S} 10 ;{ }^{1} \mathrm{H},{ }^{1} \mathrm{H}$-COSY, ${ }^{1} \mathrm{H},{ }^{13} \mathrm{C}$ HSQC, ${ }^{1} \mathrm{H},{ }^{13} \mathrm{C}-\mathrm{HMBC}$ and ${ }^{1} \mathrm{H},{ }^{1} \mathrm{H}$-NOESY). Application of Mosher's method for assignment of the absolute configuration determination on the free hydroxyl group at C-10 on the acetal-protected compound
(3) has been unsuccessful and no product formation could be detected by HPLC-HR-ESI- ( + )-Orbitrap-MS (data not shown).

The formation of the six-membered 1,3-acetal ring present in (3) allowed the analysis of the relative configuration of the triol moiety, using proton-proton coupling constants directly from ${ }^{1} \mathrm{H}-\mathrm{NMR}$ data. In addition, selTOCSY-NMR data (Supplementary Figure S9) and long-range couplings from ${ }^{1} \mathrm{H},{ }^{1} \mathrm{H}$-NOESY data (Figures $3 e$ and $\mathrm{f}$ ) were used. Because of a lack of strong NOE contacts between the methyl-group protons of $\delta_{\mathrm{Me}-1^{\prime \prime}} 1.55$ p.p.m. and the protons $\mathrm{H}-6, \mathrm{H}-7$ and H-9 (Figure $3 \mathrm{~b}$ and Table 1), an axial position of this group is not plausible and we assume a chair conformation model for the six-membered 1,3-acetal ring with the methyl group in equatorial and the phenyl group in axial position (Figure 3a and Table 1). Furthermore, the small homo-nuclear proton-proton coupling constant for ${ }^{3} J_{\mathrm{H}-7, \mathrm{H}-8}=3.3 \mathrm{~Hz}$ and ${ }^{3} J_{\mathrm{H}-8, \mathrm{H}-9}=6.3 \mathrm{~Hz}\left(48-62^{\circ}\right.$ and $30-50^{\circ}$ on the basis of the equation of Karplus ${ }^{11}$ excludes an axial-axial $\left({ }^{3} \mathrm{~J}_{\mathrm{aa}}\right)$ 


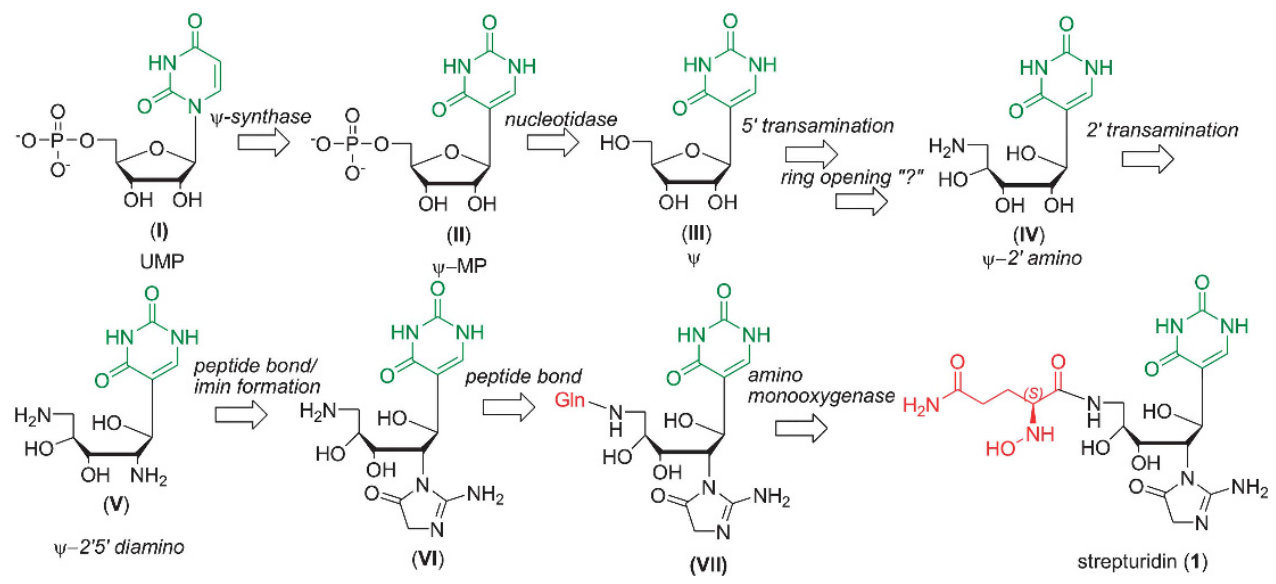

Figure 4 Proposed biosynthesis pathway of strepturidin (1).

configuration between the neighboring protons (Figure 3a). The measurements of proton-carbon coupling constants by extraction of ${ }^{1} \mathrm{H},{ }^{13} \mathrm{C}-\mathrm{HMBC}$ traces in $\mathrm{F} 2$ dimension for the correlations ${ }^{3} \mathrm{~J}_{\mathrm{H}-8, \mathrm{C}-5}$ and for ${ }^{3} J_{\mathrm{H}-8, \mathrm{C}-10}$ (Figures $3 \mathrm{c}$ and $\mathrm{d}$ ) yield, in both cases, high coupling constants of ${ }^{3} J_{\mathrm{H}, \mathrm{C}} \approx 10-13 \mathrm{~Hz}$. Although these measurements are only guidelines, they are in line with above data suggesting an axial orientation of $\mathrm{H}-8 / \mathrm{C}-5$ and of $\mathrm{H}-8 / \mathrm{C}-10$, respectively (Figure 3a). Further support for the suggested conformation (Figure 3a) is given by the analysis of ${ }^{1} \mathrm{H},{ }^{1} \mathrm{H}$-NOESY NMR data (Supplementary Figure S10) with a mixing time of $600 \mathrm{~ms}$. The data showed similarly weak NOE effects from the equatorial methyl protons at $\delta_{\mathrm{Me}-1^{\prime \prime}} 1.55$ p.p.m. to the axial $\mathrm{H}-8$ proton and to the equatorial $\mathrm{H}-7 / \mathrm{H}-9$ protons (Figure $3 \mathrm{f}$ ). In addition, a strong NOE effect from the uracil proton $\delta_{\mathrm{H}-6} 7.60$ p.p.m. to $\mathrm{H}-7$ and a weak NOE to $\mathrm{H}-8$ and $\mathrm{H}-9$ only occur in the case of the postulated arrangement (Figure 3e). Based on these results, we can deduce the relative configuration for the two hydroxyl groups at C-7 and C-9 and the 2-aminoimidazol-5-one group at C-8. Hence, both hydroxyl groups at C-7 and C-9 are syn to each other and anti to the 2-aminoimidazol5-one substituent at C-8 (Figure 4). For the interpretation of the stereochemistry see the discussion part below.

\section{Biological activity}

Bioactivity testing of pure strepturidin (1) showed the expected activity against $A$. chroococcum but no activity against the Gram-negative Escherichia coli and the Gram-positive Staphylococcus aureus or Streptomyces glaucescens. ${ }^{6}$ In an agar diffusion assay on A. chroococcum plates, $40 \mu \mathrm{g} /$ paper disc produced a $13 \mathrm{~mm}$ inhibition zone. Cytotoxicity against the mouse fibroblast cell line L929 was $>40 \mu \mathrm{g} \mathrm{ml}^{-1}$, indicating very low toxicity.

\section{DISCUSSION}

With regard to its chemical structure, strepturidin (1) belongs to the group of nucleoside antibiotics. The latter commonly target bacterial peptidoglycan cell wall biosynthesis and fungal chitin wall biosynthesis. ${ }^{12}$ The group of nucleoside natural products contain a vast number of representatives including well-known compounds, such as tunicamycin, mureidomycin A, liposidomycin B, pacidamycin and nikkomycin Z. ${ }^{12}$ The common core unit of such nucleoside antibiotics is a uridine nucleotide consisting of a $1^{\prime}-N$-glycosylation of uridine with a (3'-deoxy)-ribose unit. $^{12}$ Unlike the abovementioned nucleoside antibiotics, strepturidin (1) is a $C$-nucleoside with the $C$-glycosylation at the $5^{\prime}$ position of uracil linked to a linear diamino aldopentose of which we partially assigned the relative stereochemistry. Based on building blocks available from primary metabolism and biosynthetic analogies to other nucleoside antibiotics, we propose a biosynthesis model for (1) as outlined in Figure 4, of which the sequence of intermediate biosynthetic steps may differ: the biosynthetic logic suggests uridine monophosphate (I) with ribose as precursor of the aldopentose-moiety of strepturidin (1). This is in line with the NMR data (Figure 3 ) that suggest a syn-configuration of C-7 and C-9 and an anti-configuration of C-8 in (1). Therefore, from the four aldopentoses, arabinose and xylose are excluded as likely precursors. Considering that lyxose is a very rare aldopentose in nature, ${ }^{13}$ this strongly favors ribose as the most likely precursor. As a subsequent step, isomerization of uridine monophosphate (UMP) (I) to pseudouridine ( $\psi$-MP) (II) occurs that is catalyzed by a $\psi$ synthase-type enzyme. ${ }^{14}$ Such a biosynthetic step has been described for one of the first reported $C$-nucleosides, $5-\beta-D$ ribofuranosyluracil known as pseudouridine $(\psi)$. Interestingly, $C$-nucleosides are known to inhibit important enzyme processes, as is shown by the recent discovery of the first $C$-nucleoside hepatitits $\mathrm{C}$ virus polymerase inhibitor GS-6620. ${ }^{15}$ Further important $C$-nucleosides are ezomycin B2 (antifungal), ${ }^{16}$ showdomycin (antibiotic, cytotoxic), ${ }^{17}$ formycin (antitumor antibiotic) ${ }^{18}$ and pyrazofurin (antiviral). ${ }^{19}$ In this context, it is worth mentioning that (1) shows antibiotic activity exclusively against A. chroococcum. In subsequent steps, a nucleotidase could catalyze the hydrolysis of $\psi$-MP (II) to $\psi$ (III), which finds its analogy in the biosynthesis of caprazamycin and tunicamycin: ${ }^{12}$ The proceeding oxidation of the terminal $5^{\prime} \mathrm{OH}$-group to the $5^{\prime}$ aldehyde is followed by a transamination to $\psi$-5' -amino (IV). Subsequently, ring opening at $\mathrm{C}-2$ by formal addition of $\mathrm{H}_{2} \mathrm{O}$ occurs while the stereocenter at C-10 is maintained. ${ }^{20}$ The attachment of the unusual 2-aminoimidazol-5one building block in (VI) could be derived from condensation of glycine (Gly) and carbamoyl phosphate to the $2^{\prime}$-position of the $2^{\prime}, 5^{\prime}$-diamino aldopentose in $(\mathbf{V})$. Therefore, we hypothesize an enzyme with a transferase-like action to form the $2^{\prime}$-amino group in the aldopentose of (IV) to the intermediate $\psi-2^{\prime}, 5^{\prime}$-diamino (V), in analogy to the described $3^{\prime}$-amino formation in the proposed biosynthetic pathway of puromycin. ${ }^{21}$ Interestingly, the 2-amino pentose formation in Streptomyces alboniger by enzymatic amination is known and described to occur in cis-configuration to the $3^{\prime}$-hydroxyl group that may also define its stereochemistry. ${ }^{22}$ Also, a similar derivative of 2-aminoimidazol-5-one, the 4-formyl-4imidazolin-2-one, is found in the nikkomycin biosynthesis, derived 
from histidine. ${ }^{12}$ Finally, the amino acid Gln, the precursor of the Gln- $N_{\alpha}$-hydroxamate, which forms a peptide bond between its carboxylic group and the primary $5^{\prime}$ amine group of the aldopentose building block in (VI). This is assumed to be performed by a nonribosomal peptide synthetase (NRPS) to form (VII) before or after constituting the $N_{\alpha}$-hydroxamate through hydroxylation with an putative amino-monoxoygenase to strepturidin (1). Interestingly, $N_{\alpha}$-hydroxamate is rare in nature, whereas most hydroxamate group modifications were found in the side chain of amino acids. ${ }^{23,24}$ Although hydroxamates in general display siderophorelike functions, ${ }^{25}$ common also among other natural products like catecholate and carboxylate siderophores, the role of this moiety in strepturidin is still elusive.

In summary, the structure elucidation of strepturidin (1) renders an unprecedented structure of a novel nucleoside-type antibiotic with an exclusive antibacterial activity against A. chroococcum. Although the biosynthesis of strepturidin is still unknown, we propose similarities to biosynthesis pathways of other $(C)$-nucleoside antibiotics as mentioned above.

\section{METHODS/EXPERIMENTAL SECTION}

\section{Producing strain}

Large-scale cultivation of strain S. albus (DSM 40763) was performed by Steinhaus $^{7}$ in collaboration with the Bio-Plant of the GBF (Gesellschaft für Biotechnologisches Forschung) in 1993. A preculture was prepared in a 151 Giovanola bioreactor (Giovanola Freres, Monthey, Switzerland) charged with a complex medium consisting of mannitol $10 \mathrm{gl}^{-1}$, biopepton $5 \mathrm{gl}^{-1}$, yeast extract $5 \mathrm{gl}^{-1}$, meat extract $5 \mathrm{gl}^{-1}$, calcium chloride $0.7 \mathrm{gl}^{-1}(\mathrm{pH} 7.2)$ and tegosipon $5 \mathrm{ml}$, and inoculated with $200 \mathrm{ml}$ of a seed culture. After $14 \mathrm{~h}$, only 51 of this preculture was left because of extensive foaming that, however, was sufficient for subsequent inoculation. For the production of strepturidin (1), 801 of a complex medium consisting of mannitol $10 \mathrm{gl}^{-1}$, soy meal (full-fat) $10 \mathrm{gl}^{-1}$, meat extract $5 \mathrm{gl}^{-1}$, sodium chloride $1 \mathrm{gl}^{-1}$, calcium carbonate $1 \mathrm{gl}^{-1}$ and tegosipon $10 \mathrm{ml}$ in a 100-1 bioreactor (MBR, Zurich, Switzerland) was inoculated with the remaining 51 of the preculture. The cultivation was carried out at $37^{\circ} \mathrm{C}$ at 300 r.p.m. and an aeration of 0.5 v.v.m. (volume per volume per min). After $26 \mathrm{~h}, 130 \mathrm{gl}^{-1}$ wet cell mass and an antibiotic titer of $92 \mathrm{mgl}^{-1}$ were determined. The culture broth was harvested by centrifugation, $180 \mathrm{~g}$ of sodium heptanesulfonate was added to the $72 \mathrm{l}$ of supernatant, and the solution passed over a column $(10 \mathrm{~cm}$ diameter) with 41 of Amberlite XAD-16 at a constant flow of $8 \mathrm{lh}^{-1}$. Strepturidin (1) was bound as a heptanesulfonate ion-pair, and, after rinsing the column with water (4l), (1) eluted with $\mathrm{MeOH} /$ $\mathrm{H}_{2} \mathrm{O}, 1: 1(\mathrm{v} / \mathrm{v})$. The eluate was concentrated in vacuo, and the remaining aqueous phase was lyophilized to give $106.4 \mathrm{~g}$ of crude extract containing $5.3 \mathrm{~g}$ of (1) (yield: $80 \%$ by HPLC). To reduce the sodium heptanesulfonate load, ion-pair extraction in two batches was performed. Therefore, each batch was dissolved in $200 \mathrm{ml} \mathrm{H}_{2} \mathrm{O}$ with methyltrioctylammonium chloride (76.6 g) and each batch was extracted twice with $200 \mathrm{ml} \mathrm{CH}_{2} \mathrm{Cl}_{2}$. The aqueous phase was lyophilized to give $28.44 \mathrm{~g}$ crude extract with $2.36 \mathrm{~g}$ of (1) (yield 95\%). Preparative HPLC of this material was performed on a Eurosil C-18 column $(10 \mu \mathrm{m}, 250 \times 50 \mathrm{~mm}$, Knauer GmbH, Berlin, Germany) with a MeOH/67 mM phosphate buffer ( $\mathrm{pH}$ 5.0) (solvent $\mathrm{A}$ ) and $10 \mathrm{~mm}$ sodium heptanesulfonate (solvent B) gradient starting with 4:96 (solvent $\mathrm{A} / \mathrm{B}$ ), and ending after 5 min with 9:91 (solvent $\mathrm{A} / \mathrm{B}$ ) at a flow of $100 \mathrm{ml} \mathrm{min}^{-1}$. The detection was carried out at the UV detection wavelength $\lambda=260 \mathrm{~nm}$. For each preparative separation, 3.0-3.5 g of the crude extract was dissolved in $20 \mathrm{ml}$ of $\mathrm{H}_{2} \mathrm{O}$ to obtain in total $110 \mathrm{~g}$ of salts, which after lyophilization of the combined peak fractions contained $2.13 \mathrm{~g}$ of (1) (yield 90\%). Desalting was performed with 15-20 g portions dissolved in $350 \mathrm{ml} \mathrm{H}_{2} \mathrm{O}$ and loaded on an Amberlite XAD16 column (bed volume of $370 \mathrm{ml}$ ). The column was rinsed with two to three bed volumes of $\mathrm{H}_{2} \mathrm{O}$, and (1) eluted with $\mathrm{MeOH} / \mathrm{H}_{2} \mathrm{O}, 1: 1$ (v:v). From the combined fractions, $\mathrm{MeOH}$ was evaporated in vacuo to obtain $16.5 \mathrm{~g}$ salts containing $1.96 \mathrm{~g}$ (1) (yield 92\%). Final desalting was achieved by CMSephadex A- $25 \mathrm{NH}_{4}{ }^{+}$column chromatography (amount of gel $72 \mathrm{~g}$, column size $27.2 \times 5 \mathrm{~cm}$, flow $9-10 \mathrm{ml} \mathrm{min}^{-1}$, detection at UV detection wavelength $\lambda=254 \mathrm{~nm}$ ). The two batches ( $8 \mathrm{~g}$ per batch) were dissolved in $250 \mathrm{ml}$ water and applied to the column followed by two to three bed volumes of water with a flow of 9-10 $\mathrm{ml} \mathrm{min}^{-1}$. The pure compound (1) eluted with $50 \mathrm{~mm} \mathrm{NH}_{3}$ solution as a sharp peak in the chromatogram. The combined fractions were lyophilized to give $1.76 \mathrm{~g}$ of pure (1) as white powder (overall yield $27 \%$ ).

Analytical HPLC of (1) was performed on a Nucleosil RP-18 $(7 \mu \mathrm{m}$, $250 \times 4 \mathrm{~mm}$, Macherey-Nagel) column with the mobile phase acetonitrile/ $67 \mathrm{~mm}$ phosphate buffer $\mathrm{pH} 5$ with $10 \mathrm{~mm}$ sodium heptanesulfonate with a flow of $1.4 \mathrm{ml} \mathrm{min}^{-1}$. Detection was carried out at the UV wavelength $\lambda=262$ $\mathrm{nm}$ and the retention time of (1) at $11.7 \mathrm{~min}$.

\section{MS}

HPLC-HR-ESI-(+)-Orbitrap-MS mass spectra were recorded using a LTQ-Orbitrap XL (Thermo Scientific, Bremen, Germany) coupled to an Agilent 1260 HPLC system (Agilent Technologies, Waldbronn, Germany). The HPLC system was equipped with a Hypersil-Gold column $(5 \mu \mathrm{m}$, $50 \times 2.1 \mathrm{~mm}$, Thermo Scientific, Bremen, Germany). A $\mathrm{H}_{2} \mathrm{O} / \mathrm{MeOH}$ (solvent $\mathrm{A} /$ solvent $\mathrm{B}$ ) $+0.1 \% \mathrm{HCOOH}$ gradient was used starting with $5 \% \mathrm{~B}$ and increasing to $100 \% \mathrm{~B}$ in $6 \mathrm{~min}$, holding $100 \% \mathrm{~B}$ for $4 \mathrm{~min}$, flushing to starting conditions $5 \% \mathrm{~B}$ for $3 \mathrm{~min}$ and a flow rate of $0.25 \mathrm{ml} \mathrm{min}^{-1}$.

HPLC-LR-ESI- $(+)$ MS $^{2}$ spectra were measured on a QQQ-MS-6460 mass spectrometer (Agilent Technologies) coupled to an Agilent 1290 UHPLC-system (Agilent Technologies). The HPLC system was equipped with an Eclipse Plus C18 RRHD column $(1.8 \mu \mathrm{m}, 2.1 \times 50 \mathrm{~mm}$, Agilent Technologies). $\mathrm{A}_{2} \mathrm{O} / \mathrm{ACN}$ (solvent $\mathrm{A} /$ solvent $\mathrm{B}$ ) $+0.1 \% \mathrm{HCOOH}$ linear gradient was used starting with $5 \% \mathrm{~B}$ and increasing to $100 \% \mathrm{~B}$ in $6 \mathrm{~min}$, holding $100 \% \mathrm{~B}$ for $4 \mathrm{~min}$, flushing to starting conditions $5 \% \mathrm{~B}$ for $3 \mathrm{~min}$ and a constant flow rate of $0.25 \mathrm{ml} \mathrm{min}^{-1}$.

\section{NMR spectroscopy}

The 1D- and 2D-NMR spectra were recorded on a Bruker Avance III 500 spectrometer (Bruker, Karlsruhe, Germany) equipped with a broadband inverse detection probe with Z-Gradient at 500 and $125 \mathrm{MHz}$ for ${ }^{1} \mathrm{H}$ and ${ }^{13} \mathrm{C}$, respectively. Sample was dissolved in $600 \mu \mathrm{l} d_{6}$-DMSO for NMR experiments. Chemical shifts are given relative to TMS. For the calibration, the residual solvent peaks of $d_{6}$-DMSO (2.50 p.p.m. $\left({ }^{1} \mathrm{H}\right)$ and 39.5 p.p.m. $\left({ }^{13} \mathrm{C}\right)$ ) were used. All experiments were performed at $\mathrm{T}=298 \mathrm{~K}$.

\section{Synthesis of Gln-strepturidin (2)}

To strepturidin (1) $(5 \mathrm{mg}, 0.011 \mathrm{mmol})$ dissolved in $2 \mathrm{M} \mathrm{HCl}(5 \mathrm{ml})$, Zn dust $(0.1 \mathrm{mg})$ was added in small portions. The extent of reduction of the $N_{\alpha}$-hydroxamate group of (1) was followed by HPLC-MS. After $24 \mathrm{~h}$, the sample was centrifuged. The supernatant was purified by $\mathrm{C} 18$ solid-phase extraction), washing with $\mathrm{H}_{2} \mathrm{O}$ and eluting with $100 \% \mathrm{MeOH}$. The compound was concentrated in vacuo and then freeze-dried to obtain a yellow oily material. Compound (2) was used for total hydrolysis, derivatization and subsequent chiral GC/EI-MS analytics described in the section below.

\section{Synthesis and purification of monoacetal-strepturidin (3)}

The procedure was mainly adopted from the work published by Jundt et al. ${ }^{10}$ Strepturidin (1) (36 mg, $0.07 \mathrm{mmol}), 1,1$-dimethoxyethylbenzene $(1.15 \mathrm{ml}$, $0.7 \mathrm{mmol})$ and camphorsulfonic acid $(1.2 \mathrm{mg}, 0.005 \mathrm{mmol})$ were dissolved in $1 \mathrm{ml}$ of $d_{6}$-DMSO. After stirring overnight at $50^{\circ} \mathrm{C}$, saturated $\mathrm{Na}_{2} \mathrm{CO}_{3}$ solution was added to quench the reaction. The mixture was freeze-dried and the residue was dissolved in $\mathrm{MeOH}$ and separated by C18-HPLC to yield monoacetal-strepturidin (3) (5 mg, $0.008 \mathrm{mmol}, 11 \%$ overall yield). Preparative HPLC was performed on an Agilent HPLC 1100 system (Agilent) equipped with a Grom-Sil-120-ODS column $(5 \mu \mathrm{m}, 250 \mathrm{~mm} \times 20 \mathrm{~mm})$. A $\mathrm{H}_{2} \mathrm{O} / \mathrm{MeOH}$ (solvent $\mathrm{A} /$ solvent $\mathrm{B}$ ) gradient with a constant flow rate of $15 \mathrm{ml} \mathrm{min}^{-1}$ was used starting with $20 \% \mathrm{~B}$ and increasing to $80 \% \mathrm{~B}$ in $40 \mathrm{~min}$ holding $100 \%$ B for $5 \mathrm{~min}$, flushing to starting conditions $20 \%$ B for $3 \mathrm{~min}$. Peak collection was carried out at the UV detection wavelength $\lambda=254 \mathrm{~nm}$. The chromatogram is shown in Supplementary Figure S1. 
Total hydrolysis of Gln-strepturidin (2) for chiral GC/EI-MS analysis

Total hydrolysis of Gln-strepturidin (2) $(0.1 \mathrm{mg})$ was performed at $110^{\circ} \mathrm{C}$ in aqueous $6 \mathrm{M}$ hydrochloric acid solution $(200 \mu \mathrm{l}$, grade for amino acid analysis; Sigma-Aldrich) under vacuum for $24 \mathrm{~h}$ in glass ampoules. After $24 \mathrm{~h}$, the hydrochloric acid was removed in a gentle stream of nitrogen. Compound (2) was semi-purified by $\mathrm{C} 18$ solid-phase extraction before chiral GC/EI-MS analysis.

\section{Chiral GC/EI-MS analysis}

Chiral GC/EI-MS analysis from the total hydrolysate of Gln-strepturidin (2) was performed on a GC800 Top Voyager (Thermo Finnigan, Waltham, MA, USA) GC-mass spectrometer equipped with a chiral LIPODEX E column $(25 \mathrm{~m}$, I.D. $0.25 \mathrm{~mm})$. The scan range was $45-465 \mathrm{amu}$, detection temperature $210^{\circ} \mathrm{C}$, source temperature $220^{\circ} \mathrm{C}$, ionization energy $70 \mathrm{eV}$ and injection temperature $250{ }^{\circ} \mathrm{C}$. Helium was used as a carrier gas with constant pressure at $60 \mathrm{kPa}$. Temperature program: $70^{\circ} \mathrm{C}(2 \mathrm{~min}$ isotherm $), 90^{\circ} \mathrm{C}, 3^{\circ} \mathrm{C}$ per min ( $15 \mathrm{~min}$ isotherm), $140^{\circ} \mathrm{C}, 3^{\circ} \mathrm{C}$ per min $\left(10 \mathrm{~min}\right.$ isotherm), $200^{\circ} \mathrm{C}, 3^{\circ} \mathrm{C}$ per min $(1 \mathrm{~min}$ isotherm). The injection volume was $1 \mu \mathrm{l}$.

\section{Antimicrobial assay}

Agar test plates inoculated with $A$. chroococcum were prepared according to Reis. ${ }^{26}$ Samples to be tested were applied as $20 \mu$ l solutions on paper discs of $6 \mathrm{~mm}$ diameter. After incubation for $20 \mathrm{~h}$ at $30^{\circ} \mathrm{C}$, the diameter of the inhibition zones was measured. The minimum inhibitory amount of pure strepturidin was $1.7 \mu \mathrm{g}$, giving an $8 \mathrm{~mm}$ inhibition zone.

\section{Cytotoxicity assay}

The inhibitory activity of strepturidin (1) was tested with mouse fibroblasts L-929 (DSMZ ACC 2). Next, $60 \mu \mathrm{l}$ of a serial dilution of the compound were added to $120 \mu \mathrm{l}$ aliquots of a cell suspension (50000 cells per $\mathrm{ml}$ ) in 96-well microplates. The plates were incubated at $37^{\circ} \mathrm{C}$ and $10 \% \mathrm{CO}_{2}$ for 6 days. After that time, the MIC was estimated visually using an inverted microscope.

\section{Supporting information}

MS data and 2D NMR data are free of charge available via Internet at http:// pubs.acs.org.

\section{ACKNOWLEDGEMENTS}

We thank the members of the GBF BioPlant for the cultivation of Streptomyces albus, H Steinmetz for his support with large-scale chromatography, B. Elxnat and Ch Heuer for preparing test plates and Dr F Sasse for cytotoxicity assays. We further thank Dr D Herrmann and T Reinhardt and H-H Reis (TU Darmstadt) for valuable information. Financial support from the Cluster of Excellence ('Unifying concepts in catalysis' UniCat) granted by the German Research Council (DFG) is gratefully acknowledged.

1 Watve, M. G., Tickoo, R., Jog, M. M. \& Bhole, B. D. How many antibiotics are produced by the genus Streptomyces? Arch. Microbiol. 176, 386-390 (2001).

2 Becking, J. H. in The Prokaryotes (eds Balows, A., Trüper, H. G., Dworkin, M. \& Schleifer, K. H.) 3144-3170 (1991).
3 Kutzner, H. J. Beitrag zur Systematik und Ökologie der Gattung Streptomyces Waksman \& Henrici. PhD thesis, Landwirtschaftliche Hochschule, Hohenheim, Germany (1956).

4 Flaig, W. \& Kutzner, H. J. Beitrag zur Systematik der Gattung Streptomyces Waksman \& Henrici. Arch. Microbiol. 35, 105-138 (1960).

5 Böttiger, V. Untersuchungen an Streptomyces albus und seinem Antibiotikum. PhD thesis, Technische Universität Darmstadt, Germany (1982).

6 Gordon, R. E., Gray, T. R. E. \& Parkinson, B. in The taxonomy of soil bacteria. The Ecology of Soil Bacteria (eds Gordon, R. E. et al. ) 293-321 (Liverpool University Press: Liverpool, United Kingdom, 1967).

7 Steinhaus, B. Isolierung und Strukturaufklärung von Strepturidin - ein neues Antibiotikum aus Streptomyces albus. $\mathrm{PhD}$ thesis, Technische Universität Braunschweig, Germany (1993).

8 Herrmann, D. Zwei neue Antibiotika aus Streptomyces albus - Untersuchungen zur Optimierung der Biosynthese und Stammverbesserung. PhD thesis, Technische Universität Darmstadt, Germany (1991).

9 Lee, J., Kobayashi, Y. Tezuka, K. \& Kishi, Y. Toward creation of a universal NMR database for the stereochemical assignment of acyclic compounds: proof of concept. Org. Lett. 13, 2181-2184 (1999).

10 Jundt, L. et al. Isolation and structure elucidation of cruentarens A and B - nove members of the benzolactone class of ATPase inhibitors from the myxobacterium Byssovorax cruenta. Eur. J. Org. Chem. 22, 5036-5044 (2006).

11 Karplus, M. Vicinal proton coupling in nuclear magnetic resonance. J. Am. Chem. Soc. 85, 2870-2871 (1963).

12 Winn, M., Goss, R. J., Kimura, K. \& Bugg, T. D. Antimicrobial nucleoside antibiotics targeting cell wall assembly: recent advances in structure-function studies and nucleoside biosynthesis. Nat. Prod. Rep. 27, 279-304 (2010).

$13 \mathrm{Khoo}, \mathrm{K}$. H. et al. Chemistry of the lyxose-containing mycobacteriophage receptors of Mycobacterium phleilMycobacterium smegmatis. Biochemistry 35, 11812-11819 (1996).

14 Cortese, R., Kammen, H. O Spengler, S. J. \& Ames, B. N. Biosynthesis of pseudouridine in transfer ribonucleic acid. J. Biol. Chem. 25, 1103-1108 (1974).

15 Cho, A. et al. Discovery of the first C-nucleoside HCV polymerase inhibitor (GS-6620) with demonstrated antiviral response in HCV infected patients. J. Med. Chem. (e-pub ahead of print 1 May 2013; doi:10.1021/jm400201a).

16 Hanessian, S., Dixit, D. M. \& Liak, T. J. Studies directed toward the total synthesis of the ezomycins, the octosyl acids and related antibiotics. Pure Appl. Chem. 53, 129-148 (1981).

17 Darnall, K. R., Townsend, L. B. \& Robins, R. K. The structure of showdomycin, a novel carbon-linked nucleoside antibiotic related to uridine. Proc. Natl Acad. Sci. USA 57, 548-553 (1967).

18 Ochi, K., Yashima, S. \& Eguchi, Y. Biosynthesis of formycin. Incorporation and distribution of 13C-, 14C-, and 15N-labeled compounds into formycin. J. Biol. Chem. 254, 8819-8824 (1979).

19 Westhead, J. E. \& Price, H. D. Quantitative assay of pyrazofurin a new antiviral, antitumor antibiotic. Antimicrob. Agents Chemother. 5, 90-91 (1974).

20 Prior, J. J. \& Santi, D. V. On the mechanism of the acid-catalyzed hydrolysis of uridine to uracil. Evidence for 6-hydroxy-5,6-dihydrouridine intermediates. J. Biol. Chem. 259, 2429-2434 (1984).

21 Tercero, J. A., Espinosa, J. C., Lacalle, R. A. \& Jiménez, A. The biosynthetic pathway of the aminonucleoside antibiotic puromycin, as deduced from the molecular analysis of the pur cluster of Streptomyces alboniger. J. Biol. Chem. 3, 1579-1590 (1996).

22 Rebello, P. F., Pogell, B. M. \& Mukherjee, P. P. Formation of 2-amino-2-deoxy-d-ribose 5-phosphate and 2-amino-2-deoxy-d-lyxose 5-phosphate by extracts of Streptomyces alboniger. Biochim. Biophys. Acta 177, 468-485 (1969).

23 Barona-Gómez, F., Wong, U., Giannakopulos, A. E., Derrick, P. J. \& Challis, G. L. Identification of a cluster of genes that directs desferrioxamine biosynthesis in Streptomyces coelicolor M145. J. Am. Chem. Soc. 126, 16282-16283 (2004).

24 Agnoli, K., Lowe, C. A., Farmer, K. L., Husnain, S. I. \& Thomas, M. S. The ornibactin biosynthesis and transport genes of Burkholderia cenocepacia are regulated by an extracytoplasmic function sigma factor which is a part of the Fur regulon. J. Bacteriol. 188, 3631-3644 (2006).

25 Neilands, J. B. Siderphores: structure and function of microbial iron transport compounds. J. Biol. Chem. 270, 26723-26726 (1995).

26 Reis, K. H. Versuche zur Aufreinigung eines von Streptomyces albus gebildeten Antibiotikums. Diploma thesis, Technische Universität Darmstadt, Germany (1988).

Supplementary Information accompanies the paper on The Journal of Antibiotics website (http://www.nature.com/ja) 